\title{
Flora do Rio de Janeiro: Aizoaceae
}

\author{
Flora of Rio de Janeiro: Aizoaceae
}

Ricardo Sousa Couto ${ }^{1,4}$, Aluisio José Fernandes Junior ${ }^{2}$ \& Rosana Conrado Lopes ${ }^{3}$

\begin{abstract}
Resumo
O presente estudo tem como objetivo contribuir para o conhecimento das espécies de Aizoaceae ocorrentes no estado do Rio de Janeiro. O trabalho tem como base a análise de coleções depositadas em herbários e coletas de campo, além da consulta a dados de literatura. Foi registrada uma espécies: Sesuvium portulacastrum. São apresentadas descrições, comentários, além de dados sobre hábitat e distribuição geográfica da espécie.
\end{abstract}

Palavras-chave: flora, Sesuvium, sudeste, taxonomia.

\begin{abstract}
This work aims to contribute to the flora of Aizoaceae from Rio de Janeiro state. It is based on the analysis of herbarium specimens and fieldwork, a s well as on the relevant literature. One species were recorded: Sesuvium portulacastrum. Descriptions and comments, besides data on habitat and geographical distribution of the species are provided.
\end{abstract}

Key words: flora, Sesuvium, southeast, taxonomy.

\begin{abstract}
Aizoaceae
Ervas eretas, prostradas ou estoloníferas, perenes ou anuais, carnosas. Folhas alternas ou opostas, completas, pecioladas ou sesseis, com ou sem bainha. Inflorescências cimosa, uniflora, raro plurifloras, axilares, raro terminais. Flores bissexuadas, períginas; cálice persistente, frequentemente gamossépalo, 5-8 lóbulos; corola ausente; estames 5 ou polistêmone, cíclicos, livres ou concrescidos na base, geralmente com numerosos estaminódios petalóides; ovário súpero, óvulos numerosos ou solitários. Fruto cápsula circuncisa ou loculicida, raramente com arilo; sementes com endosperma.
\end{abstract}

Aizoaceae pertence à ordem Caryophyllales, possui cerca de 123 gêneros e 2020 espécies distribuídas principalmente em regiões áridas do sudeste africano, com representantes nas regiões tropicais e temperadas de todo o mundo (Stevens 2001 onwards). No Brasil ocorrem três gêneros (Sesuvium L., Tetragonia L. e Trianthema L.), todos com uma espécie para o país (Zappi 2010). No estado do Rio de Janeiro, Aizoaceae está representada por Sesuvium portulacastrum (L.) L., que distribui-se em todas as restingas do Sudeste do Brasil (SegadasVianna et al. 1967). Lampranthus productus N.E. Br. (cacto-margarida) e Aptenia cordifolia (L.f.) Schwantes (rosinha-de-sol) são cultivadas como ornamentais no estado. Tetragonia tetragonoides (Pall.) Kuntze (espinafre-da-Nova-Zelândia), é cultivada como alimentícia, sendo considerada espécie invasora no litoral de São Paulo (Souza \& Lorenzi 2008).

\section{Sesuvium $\mathrm{L}$.}

Ervas, pouco ramificadas, frequentemente emitindo raízes nos nós. Folhas completas, bainha aberta, estipuladas, elípticas ou obovadas. Inflorescência em glomérulos ou uniflora. Flores sésseis ou pediceladas; sépalas 5 , gamossépalas, oblongas, ápice agudo, face externa verde, apendiculada no ápice, face interna rósea; estames

\footnotetext{
${ }^{1}$ Universidade Federal do Rio de Janeiro, Prog. Pós-graduação em Botânica, Depto. Botânica, Museu Nacional, Quinta da Boa Vista s/n, São Cristóvão, 20940-040, Rio de Janeiro, RJ, Brasil.

${ }^{2}$ Universidade Federal do Rio de Janeiro, Prog. Pós-graduação em Botânica, Depto. Botânica, Museu Nacional, Quinta da Boa Vista s/n, São Cristóvão, 20940-040, Rio de Janeiro, RJ, Brasil. ajfernandesjunior@gmail.com

${ }^{3}$ Universidade Federal do Rio de Janeiro, IB-CCS, Depto. Botânica, Ilha do Fundão, 21941-590, Rio de Janeiro, RJ, Brasil. rosana@biologia.ufrj.br

${ }^{4}$ Autor para correspondência: rcouto@jbrj.gov.br
} 
livres, ou inseridos no cálice; ovário 3-5-locular, pluriovular; estiletes 3-5, filiformes. Cápsula circuncisa, membranácea, elipsóide-oblonga; sementes numerosas, reniformes, lisas, envolvidas por arilo negro.

Segundo Stevens, (2001 onwards) Sesuvium é composto por 12 espécies, ocorrendo em regiões tropicais e subtropicais de ambos os hemisférios, sempre associada a regiões costeiras (Reitz 1984).

Sesuvium portulacastrum (L.) L. - Syst. Nat., ed. 10, 2: 1058. 1759.

Portulaca portulacastrum L. - Sp. Pl. 1: 446. 1753.

A espécie é conhecida em todo o Brasil como beldroega-da-praia, beldroega-miúda, beldro-dapraia, capim-salgado ou vídrio (Reitz 1984). As folhas cruas ou cozidas são utilizadas na alimentação, e também servem como emolientes e antiescorbúticas (Reitz 1984).

Ervas prostradas ou estoloníferas, perenes, glabras. Folha 2-4 mm; lâmina 5-30 × 2-6 mm, obovada, ápice agudo, base dilatada, bainha papirácea. Inflorescência uniflora, axilar. Flores vermelhas ou lilases; pedicelo $4 \times 10 \mathrm{~mm}$; sépalas 5 , lóbulos ovados $4-7 \times 3-4,5 \mathrm{~mm}$, persistentes e reflexos no fruto, base auriculada, ápice com apêndices corniformes; polistêmone, livres ou subconados, inseridos no cálice; ovário subgloboso, 3-3,5 × 2,5-3 mm, estiletes 3-4, 1,5-3,5 mm, eretos ou divergentes. Cápsula $6,5 \times 3 \mathrm{~mm}$, deiscente no terço inferior; semente 8-30, negra, lenticularreniforme, $1-1,5 \mathrm{~mm}$ diâm.

A espécie distribui-se pelas regiões tropicais e subtropicais de todo o mundo, ocorrendo exclusivamente na vegetação herbácea costeira, porém, também é encontrada em áreas rochosas (Lonard \& Judd 1997). No Brasil ocorre em todo o litoral, sendo freqüentemente encontrada em solos arenosos com grande concentração de sal, em solos muito úmidos e por vezes inundados, em solos demasiado secos, na vegetação pioneira herbácea das antedunas e dunas (Segadas-Vianna et al. 1967). No Rio de Janeiro ocorre em: I36, O19, O29, P4, Q5, Q27, R18, S27, S28, T11, T17, T23, T24, T27, U12 e U15. Coletada com flores e frutos durante todo o ano. Material selecionado: Araruama, na cidade, VI.1959, fl., F. Segadas-Vianna 3580. (R); Armação dos Búzios, Praia Brava, 28.X.10, fl. e fr., R.S. Couto 454 (RFA); Arraial do Cabo, Praia Grande, Apa de Massambaba, 10.XII.1999, fl. e fr., D. Fernandes 345 (RB); Cabo Frio, Km 21,5 da estrada S. Pedro da Aldeia, s.d., fl. e fr., F. Palmieri (RB 182297); Campos dos Goytacazes, sem local, II.1939, fl., A.J. de Sampaio 7844 (R); Casimiro de Abreu, Barra de São João, 27.VII.1965, fl. e fr., F. Segadas-Vianna 4355
(R); Itaboraí, rio Guaxindiba, 17.XII.1976, fl., D. Araujo 1445 (GUA); Itaguaí, Coros Grande, 25.XI.1981, fl., J. de A. Peixoto 93 (GUA); Itatiaia, s. loc., IV.1926, fl., A.J. de Sampaio 4801 (R); Macaé, margens da Lagoa do Visgueiro, 3.VI.1981, fl. e fr., D. Araujo \& N.C. Maciel 4521 (GUA); Niterói, Restinga da Praia de Piratininga, 27.X.1963, fl. e fr., G.F.J. Pabst (HB 28123); Resende, Mauá, 1.I.1887, fl., J. Schwacke (R 58903); Rio de Janeiro, Ilha do Governador, próximo ao Jockey Club, 7.IX.1960, fl. e fr., G.F.J. Pabst 5422 (HB); Saquarema, Reserva Ecol. Est. de Massambaba área entre cordões, 26.X.1993, fl. e fr., M. Jalu 113 (RB); Teresópolis, sem local, IV.1917, fl., A.J. de Sampaio 2354 (R).

\section{Agradecimentos}

Os autores agradecem aos Curadores dos Herbários consultados, ao Instituto de Biologia da Universidade Federal do Rio de Janeiro, e ao Programa de Pós-graduação em Botânica do Museu Nacional do Rio de Janeiro, o apoio logístico durante o desenvolvimento deste trabalho.

\section{Referências}

Bittrich, V. \& Hartmann, H.E.K. 1989. The Aizoaceae - a new approach. Journal of the Linnean Society. Botany. 97: 239-254.

Dequan, L. \& Hartmann, H.E.K. 2004. Flora of China, Aizoaceae. Vol. 5. Science Press, Beijing \& St. Louis Missouri Botanical Garden Press, St. Louis. 440p.

Klak, C.; Khunou, A.; Reeves, G. \& Hedderson, T. 2003. A phylogenetic hypothesis for the Aizoaceae (Caryophyllales) based on four plastid DNA regions. American Journal of Botany 90: 1433-1445.

Lonard, R.I. \& Judd, F.W. 1997. The Biological flora of coastal dunes and wetlands. Sesuvium portulacastrum (L.) L. Journal of Coastal Research 13: 96-104.

Reitz, R. 1984. Aizoáceas. In: Reitz, R. (ed.). Flora Ilustrada Catarinense. Herbário Barbosa Rodrigues, Itajaí. 9p.

Rohrbach, P. 1872. Ficoidaceae. In: Martius, C.F.P.; Eichler, A.G. \& Urban, I. (ed.). Flora brasiliensis. Lipsiae, Frid. Fleischer. Vol. 14, pp. 309-316, tab. 70-71.

Segadas-Vianna, F.; Ormond, W. \& Dau, L. 1967. Aizoaceae. In: Segadas-Viana, F.; Ormond, W.; Dau, L. (ed.). Flora ecológica de restingas do Sudeste do Brasil. Vol. 6. Museu Nacional, Rio de Janeiro. Pp. 1-9.

Souza, V.C. \& Lorenzi, H. 2008. Botânica Sistemática. Instituto Plantarum, Nova Odessa. 704p.

Stevens, P.F. 2001. Angiosperm phylogeny website. Disponível em <http://www.mobot.org/MOBOT/ research/APweb/>. Acesso em 22 agosto 2011.

Teixeira, L. 1959. Aizoaceae da cidade do Rio de Janeiro. Rodriguésia 33 e 34: 289-298.

Zappi, D.C. 2010. Aizoaceae. In: Forzza, R.C. et al. (org.). Catálogo de plantas e fungos do Brasil. Vol. 1. Jardim Botânico do Rio de Janeiro, Rio de Janeiro. 585p. 
Lista de exsicatas

Alves, L.C. 55 (1.1). Araujo, D. 1445 (1.1), 4521 (1.1), 10812 (1.1), 6864 (1.1), 3941 (1.1), 993 (1.1), 3635 (1.1), 4789 (1.1). Bautista, H.P. 1361 (1.1). Botelho, M. s.n. (1.1). Carvalho, P. s.n. (1.1). Casari, M.B. 561 (1.1), 568 (1.1). Couto, R.S. 454 (1.1), 456 (1.1). Damázio, E. 12 (1.1). Duarte, M.C. 13 (1.1). Emygdio, L. 428 (1.1). Fernandes, D. 2 (1.1), 345 (1.1). Form, E. 1249 (1.1). Jalu, M. 113 (1.1). Occhioni, P. 3846 (1.1), 3524 (1.1), s.n. (1.1). Pabst, G.F.J. 5422 (1.1), s.n. (1.1). Palmieri, F. s.n. (1.1). Peixoto, J. de A. 93 (1.1). Pereira, A. s.n. (1.1). Pinto, G.C.P. 375/83A (1.1). Rizzini, C.T. s.n. (1.1). Sampaio, A.J. de 2354 (1.1), 4801 (1.1), 7844 (1.1). Schwacke, J. s.n. (1.1). Segadas-Vianna, F. 3580 (1.1), 4355 (1.1). Sobrinho, J.P.L. 1300 (1.1). Sucre, D. 10018 (1.1). Trinta, Z.A. 534 (1.1). Ule, E. s.n. (1.1). 